\title{
Selected salivary parameters in children with idiopathic nephrotic syndrome: a preliminary study
}

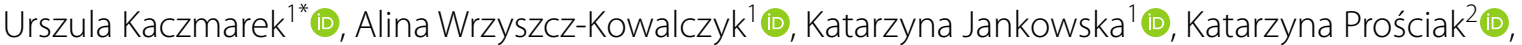 \\ Monika Mysiak-Dębska ${ }^{1}$, Iwona Przywitowska ${ }^{1}$ and Irena Makulska² ${ }^{2}$
}

\begin{abstract}
Background: Disturbances in the levels of serum constituents occurring in chronic renal diseases can be reflected in the saliva composition. The aim of this study was to assess some selected salivary components in children suffering from idiopathic steroid-sensitive nephrotic syndrome (iNS).

Methods: A case-control study was performed on iNS and healthy participants. In unstimulated mixed saliva, $\mathrm{pH}$, buffer capacity, total protein, a-amylase, peroxidase, calcium, magnesium, inorganic phosphate, fluoride, urea, uric acid and salivary flow rate were measured. Oral condition was assessed using dmft, DMFT, API and Gl indices, usage of fluoride specimens and frequency of tooth brushing. Statistical analysis was performed by Shapiro-Wilk, BrownForsythe, Student's t, ANOVA, Tukey's and Pearson's chi-square tests, Pearson's and Spearman's correlations, logistic regression and receiver operating characteristic (ROC) curve analysis.

Results: The study involved 94 participants of both genders aged 4-17 (47 cases in relapse or remission phase of iNS and 47 controls) who were treated in the clinic of pediatric nephrology or outpatient dental clinic. Neither group differed in the number of caries-affected primary and permanent teeth, gingival condition or use of fluoride specimens. The iNS group presented lower levels of magnesium $(0.41 \pm 0.34 \mathrm{vs} .0 .60 \pm 0.38 \mathrm{mg} / \mathrm{dL}, \mathrm{P}<0.05)$ and fluoride $(0.15 \pm 0.10$ vs. $0.21 \pm 0.10 \mathrm{ppm}, \mathrm{P}<0.01)$ and higher contents of urea $(35.19 \pm 15.55 \mathrm{vs} .25 .21 \pm 10.78 \mathrm{mg} / \mathrm{dL}, \mathrm{P}<0.01)$ and uric acid $(2.90 \pm 1.23$ vs. $2.34 \pm 1.04 \mathrm{mg} / \mathrm{dL}, \mathrm{P}<0.05)$ than the controls. In the iNS participants with relapse, a higher peroxidase activity and lower magnesium content than in the remission phase were found. ROC analysis showed a weak discriminatory power of these salivary constituents for the differentiation of participants with and without disease (accuracy from 66.0 to 67.0\%, area under the ROC curve (AUC) from 0.638 to 0.682 ) and the relapse and remission phases (accuracy $70.2 \%$ and $68.1 \%$ and AUC 0.717 and 0.675 , respectively).
\end{abstract}

Conclusions: Levels of urea, uric acid, magnesium and fluoride in saliva can be associated with the course of iNS. Salivary levels of peroxidase and magnesium can be related to the phase of the disease. However, the measurements of these parameters cannot be useful as a noninvasive tool in diagnosing iNS and the phase of the disease.

Keywords: Idiopathic nephrotic syndrome, Salivary components, Children

*Correspondence: urszula.kaczmarek@umed.wroc.pl; ukaczm@tlen.pl ${ }^{1}$ Department of Conservative Dentistry and Pedodontics, Wroclaw Medical University, Krakowska 26, 50-425 Wrocław, Poland

Full list of author information is available at the end of the article

\section{Background}

Nephrotic syndrome is a common chronic glomerular disease occurring in childhood [1,2]. This disease can be caused by minimal-change nephrotic syndrome, focal segmental glomerulosclerosis, membranous 
nephropathy, genetic disorders and secondary diseases linked to infections, drugs, and neoplasia; however, the disease can also be idiopathic. The disease involves immune dysregulation, systemic circulating factors, or inherited structural abnormalities of the podocyte $[2,3]$.

Clinical and biochemical symptoms of the disease result from proteinuria (mostly albuminuria), which exceeds the possibility of compensatory mechanisms in the body. An abnormality of the permselectivity barrier of the glomerular capillary wall, which is unable to restrict the loss of protein, causes the loss of protein with urine. Hypoalbuminemia and hyperlipidemia are found in the blood. Clinical symptoms can include edema of the legs and face, ascites, weight gain, feeling very tired, not feeling hungry, and foamy or bubbly urine [1].

The two types of primary idiopathic nephrotic syndrome are recognized as follows: steroid-sensitive (the most common) and steroid-resistant types. The longterm prognosis for steroid-sensitive cases regarding kidney function is good, but steroid-resistant cases constitute a future risk of chronic or end-stage renal disease. However, even the steroid-sensitive type can have a frequently relapsing course requiring the administration of alternative immunosuppressive agents $[1,2,4,5]$.

Whole saliva is a mixture of the secretion of the major and minor salivary glands, gingival crevicular fluid, mucosal transudate, desquamated epithelial cells, bacteria, viruses and fungi and other cellular components. Some salivary constituents are synthesized by salivary glands, while others originate from the blood through transcellular, passive intracellular diffusion and active transport, paracellular routes by extracellular filtration within the salivary glands or through the gingival crevice [6-8]. Therefore, salivary constituents of serum origin can reflect the abnormalities in the blood composition associated with systemic diseases $[9,10]$. In patients with chronic kidney disease (CKD), higher contents of urea, uric acid and creatinine in saliva were found [11-13]. Salivary levels of cortisol, nitrite, uric acid, sodium, chloride, $\mathrm{pH}$, amylase, and lactoferrin have been reported to be markers related to end-stage renal disease [14]. An elevated level of phosphate in saliva was proposed as a biomarker for the initiation of treatment of hyperphosphatemia, which is an important contributor to cardiovascular calcification in chronic renal failure [14, 15]. Therefore, saliva analysis could be used as a noninvasive alternative to plasma analysis for the diagnosis and monitoring of patients with CKD. However, in the case of nephrotic syndrome, it is indefinite whether the abnormality of capillary permeability is restricted to the glomerular capillary wall or can involve other capillaries, including those in the salivary glands.
The study aimed to evaluate selected protein and nonprotein salivary components in children with idiopathic steroid-sensitive nephrotic syndrome compared to healthy controls. We also compared the levels of salivary parameters between the patients in the remission versus relapse phases of the disease. In addition, we assessed the potential usefulness of the studied salivary constituents as markers discriminating diseased and nondiseased children. The null hypothesis has been assumed that there are no differences in the studied salivary constituents between iNS patients and controls.

\section{Methods \\ Study design}

The presented case-control study is a part of the project that included clinical examination of oral health parameters, sociodemographic questionnaires and assessment of selected salivary components in idiopathic steroid-sensitive nephrotic syndrome (iNS) patients and controls.

The iNS participants were treated in the Department and Clinic of Pediatric Nephrology, and controls were healthy outpatients attending the dental clinic at the Department of Conservative Dentistry and Pedodontics of Wroclaw Medical University, Poland. The examinations were performed from May 2018 to April 2019. The detailed data on oral health parameters and questionnaire items were published earlier [16]. In this paper, we used only several basic oral health parameters, which could potentially influence the studied salivary components.

The STROBE guidelines for case-control studies were followed [17].

\section{Participants}

The recruited participants $(n=110)$, both genders, were between the ages of 4 and 17 . Nevertheless, 9.1\% $(n=10)$ of the parents refused to consent to the study, and 5.4\% $(n=6)$ of the children refused to be examined. Finally, 94 participants were enrolled in the study. Half of them were patients suffering from iNS and were either in remission $(n=26)$ or in the relapse phase of the disease $(n=21)$, being treated in the Clinic of Pediatric Nephrology, and the remaining participants were healthy $(n=47)$. The inclusion criteria for the iNS patients were the disease diagnosed at least two years earlier than this study and no other acute systemic diseases present at that moment. The iNS phase was recognized by clinical symptoms and laboratory blood tests.

The control group included clinically healthy participants $(n=47)$ who were outpatients of the dental clinic without a history of impaired renal function or proteinuria or acute or chronic systemic diseases (based on medical interviews of a parent and a child's health record 
book) and at the age range and gender corresponding to the iNS patients.

All participants involved in the study had to provide written informed consent from a parent (in addition to a separate written consent from participants age 16 and over), be willing to undergo the oral clinical examination and salivary sample collection, and had to respond to questionnaire items. Participants who did not meet the inclusion criteria were excluded from the study.

\section{Ethics approval}

Approval to conduct the study was obtained from the Bioethics Committee of Wroclaw Medical University (permission no. KB-343/2016). All parents of the recruited participants provided their written consent to participate in the study, and the participants were willing to submit to the investigation. Participation in the study was voluntary and anonymous, and the collected data were treated confidentially.

\section{Sample size estimation}

Sample size determination was based on a t-test for independent groups using a special computer program [18]. The expected difference between means for the two groups for salivary urea content was set at 10.0 (variance equal to 220). The power of the test was set at $90 \%$, and the confidence level was set at $95 \%$. With such assumptions, the required sample size for each group was equal to $\mathrm{n}=47$.

\section{Questionnaire items}

Data on gender, age, frequency of toothbrushing, use of fluoridated toothpaste and topical professional application of fluoride specimens, and diet were reported by the parents of the participants. The detailed questionnaire items were published earlier [16].

\section{Oral health status}

The clinical oral examination was carried out with the use of artificial light, a plain mirror and a ball-ended dental probe (WHO CPI probe). This process included the assessment of the number of primary and permanent caries-affected teeth (dmft and DMFT values) according to World Health Organization criteria (WHO) [19], oral hygiene using the Approximal Plaque Index-API by Lange et al., 1974 [20] and gingival condition according to the Gingival Index-GI, by Löe and Silness, 1963) [20]. Additional oral health parameters had been analyzed previously [16].

\section{Salivary sample collection}

The mixed saliva was collected after rinsing the mouth with distilled water without external stimulation at least
$2 \mathrm{~h}$ after breakfast. The child sat with the head bent down and the mouth open and deposited saliva by spitting into a graded test tube that was stored on crushed ice. The salivary flow rate was calculated as $\mathrm{ml} / \mathrm{min}(\mathrm{V})$ based on the measurement of the volume of the collected saliva sample and the time needed for its collection. The saliva samples were centrifuged for $15 \mathrm{~min}$ at a speed of $3500 \mathrm{rpm}$ before the biochemical assays.

\section{Salivary parameters}

The following salivary parameters were assessed: $\mathrm{pH}$ (by potentiometric method), buffer capacity (BC, by titration method), total protein (P, by Lowry's et al. method) [21], $\alpha$-amylase (Amy, by the assay kit based on Caraway's method), salivary peroxidase (SPO, by $\mathrm{Nbs}_{-} \mathrm{SCN}^{-}$ method) [22], calcium ( $\mathrm{Ca}$, by the assay kit based on the formation of the chromogenic complex between calcium ions and o-cresolphthalein), magnesium ( $\mathrm{Mg}$, by the assay kit based on the reaction of magnesium with xylidyl blue-I), inorganic phosphate (iPh, by the assay kit based on the formation of the chromogenic complex of ammonium molybdate with phosphate), fluoride (F, by the ionic selective electrode Orion 9609), urea (U, by the assay kit based on urease activity), and uric acid (UA, by the assay kit based on uricase activity).

\section{Assessment of selected components in the blood}

Venous blood samples were collected from ill subjects after an overnight fast. After centrifugation, the protein, albumin, urea, uric acid, calcium, magnesium, inorganic phosphate, total cholesterol, triglycerides and creatinine were measured in plasma using an automated standardized multichannel analyzer (Konelab 30i; Thermo Fisher Scientific Inc., bioMerieux, Marcy l'Etoile, France). The estimated glomerular filtration rate (eGFR) was also determined [23]. The blood tests were performed on the same day as salivary sample collection.

\section{Statistical analysis}

The consistency of the obtained results with a normal distribution was verified with the use of the ShapiroWilk test and the homogeneity of variance using the Brown-Forsythe test. The quantitative continuous variables with distributions that were not significantly different from normal are presented as the mean and standard deviation, and the qualitative variables are presented as numbers and percentages. Significant between-group differences in the mean values of the variables with a normal distribution were verified using Student's t-test, ANOVA and Tukey's test. The association between variables was tested with the chi square Pearson's test and Spearman's or Pearson's correlation coefficients. Logistic bivariate and multivariate regression analyses for dependent 
variables (presence or absence of the disease) and independent variables (salivary parameters) were carried out. Receiver operating characteristic (ROC) curve analysis was used to evaluate the diagnostic potential of selected salivary constituents to classify the iNS participants compared to controls and the patients with relapse compared to remission. The overall results were assessed by the area under the ROC curve (AUC) and the cutoff values, which were determined based on the best trade-off between sensitivity and specificity. The level of significance was set at $\mathrm{P}<0.05$. All analyses were computed with Statistica 13 software (PL StatSoft).

\section{Results}

\section{Distribution of the participants}

Ninety-four participants were included in the study; half of them suffered from idiopathic steroid-sensitive nephrotic syndrome, and the remaining participants were healthy. The first episode of the disease occurred between the ages of 4 and 15 (mean $3.8 \pm 3.0$ years old). The duration of the disease at the time of the examination ranged from 2 to 15 years (mean $6.4 \pm 4.0$ years), and the number of relapses ranged from 1 to 15 (mean $3.8 \pm 2.9$ ).

The mean age of the iNS patients was $9.6 \pm 3.9$ years and that of healthy participants was $10.8 \pm 3.7$ years and did not vary substantially $(P>0.05)$.
The iNS patients at the time of the examination were taking various medications depending on their condition, and they were on diets containing low salt, fat, and cholesterol and rich in protein, fruits, and vegetables, unlike the controls.

\section{Oral health parameters}

The iNS patients and healthy participants did not differ significantly with regard to the number of caries-affected primary and permanent teeth $(\mathrm{dmft}+\mathrm{DMFT})$ and components $(\mathrm{dt}+\mathrm{DT}, \mathrm{mt}+\mathrm{MT}$ and $\mathrm{ft}+\mathrm{FT})$, API value and GI score, usage of fluoridated dentifrice and topical professional application of fluoride specimens. However, the iNS group showed a significantly lower mean number of filled primary and/or permanent teeth $(\mathrm{P}<0.001)$ and less frequent tooth brushing, that is, less than twice a day $(\mathrm{P}<0.05)$ (Table 1).

\section{Salivary parameters}

The participants suffering from iNS revealed significantly lower concentrations of magnesium $(\mathrm{P}<0.05)$ and fluoride $(\mathrm{P}<0.01)$ and higher urea $(\mathrm{P}<0.01)$ and uric acid $(\mathrm{P}<0.05)$ compared with the controls. The patients in the relapse phase presented a higher SPO level and lower magnesium content than those in the remission phase of the disease, and both subgroups showed a lower content

Table 1 Characteristics of the studied participants

\begin{tabular}{|c|c|c|c|c|c|c|}
\hline & & \multicolumn{2}{|l|}{ iNS } & \multicolumn{2}{|l|}{ Control } & \multirow[t]{2}{*}{ P-value } \\
\hline & & n & $\%$ & n & $\%$ & \\
\hline \multirow[t]{2}{*}{ Gender } & Male & 25 & 53.2 & 18 & 38.3 & 0.147 \\
\hline & Female & 22 & 46.8 & 29 & 61.7 & \\
\hline Age (years) & Mean $\pm S D$ & $9.6 \pm 3.9$ & & $10.8 \pm 3.7$ & & 0.142 \\
\hline $\begin{array}{l}\text { Number of caries-affected primary and/or permanent } \\
\text { teeth }(\mathrm{dmft}+\mathrm{DMFT})\end{array}$ & Mean \pm SD & $4.6 \pm 3.5$ & & $6.0 \pm 4.1$ & & 0.126 \\
\hline Primary and/or permanent decayed teeth (dt + DT) & Mean $\pm S D$ & $3.5 \pm 3.2$ & & $2.4 \pm 2.4$ & & 0.095 \\
\hline Primary and/or permanent missing teeth $(\mathrm{mt}+\mathrm{MT})$ & Mean $\pm S D$ & $0.02 \pm 0.1$ & & $0.2 \pm 0.8$ & & 0.543 \\
\hline Primary and/or permanent filled teeth $(\mathrm{ft}+\mathrm{FT})$ & Mean $\pm S D$ & $1.1 \pm 1.6$ & & $3.5 \pm 3.6$ & & $<0.001^{* *}$ \\
\hline API (\%) & Mean $\pm S D$ & $54.0 \pm 35.7$ & & $43.4 \pm 27.6$ & & 0.108 \\
\hline Gl & Mean $\pm S D$ & $0.7 \pm 1.0$ & & $0.3 \pm 0.6$ & & 0.050 \\
\hline \multirow[t]{2}{*}{ Tooth brushing } & Twice a day & 37 & 78.7 & 44 & 93.6 & $0.026^{*}$ \\
\hline & Once a day or every few days & 10 & 21.3 & 3 & 6.4 & \\
\hline \multirow[t]{2}{*}{ Dentifrice } & Fluoridated & 43 & 91.5 & 42 & 89.4 & 0.603 \\
\hline & No fluoride & 4 & 8.5 & 5 & 10.6 & \\
\hline \multirow[t]{2}{*}{ Topical professional application of fluoride specimens } & Yes & 16 & 34.0 & 17 & 36.2 & 0.541 \\
\hline & No or does not know & 31 & 66.0 & 30 & 63.8 & \\
\hline
\end{tabular}

iNS Idiopathic nephrotic syndrome, dmft number of decayed, missing due to caries and filled primary teeth, DMFT number of decayed, missing due to caries and filled permanent teeth, $d t$ number of decayed primary teeth, $D T$ number of decayed permanent teeth, $m t$ number of missing primary teeth, $M T$ number of missing permanent teeth, $f t$ number of filled primary teeth, $F T$ number of filled permanent teeth, $A P I$ approximal plaque index, GI gingival index, $P$-value level of statistical significance

*Significant difference at $P<0.05$

**Significant difference at $P<0.001$ 
of fluoride and higher urea and uric acid levels than the controls (Table 2). Moreover, the patients in the relapse phase revealed a higher SPO level and a lower concentration of magnesium than the healthy participants. Bivariate logistic regression showed that out of all analyzed salivary variables considered separately, only levels of salivary urea, uric acid, magnesium and fluoride were associated with the disease. In the multivariate regression model (where salivary variables were considered together as independent variables), the levels of salivary urea and magnesium revealed significant associations with the presence of the disease (Table 3). However, ROC curve analysis indicated that the salivary levels of magnesium, fluoride, urea and uric acid were weak classifiers to

\section{Table 2 Comparison of salivary parameters between the iNS and control participants}

\begin{tabular}{|c|c|c|c|c|}
\hline \multirow[t]{2}{*}{ Studied groups } & \multicolumn{3}{|l|}{ iNS } & \multirow[t]{2}{*}{ Control $n=47$} \\
\hline & Remission $\mathrm{n}=26$ & Relapse $n=21$ & Total $n=47$ & \\
\hline Salivary parameters & Mean $\pm S D$ & Mean $\pm S D$ & Mean $\pm S D$ & Mean $\pm S D$ \\
\hline Flow rate (ml/min) & $0.41 \pm 0.26$ & $0.48 \pm 0.30$ & $0.44 \pm 0.27$ & $0.46 \pm 0.19$ \\
\hline $\mathrm{pH}$ & $7.27 \pm 0.71$ & $7.28 \pm 0.70$ & $7.28 \pm 0.70$ & $7.50 \pm 0.50$ \\
\hline Buffer capacity (mmol/L) & $6.67 \pm 5.83$ & $4.95 \pm 2.87$ & $5.90 \pm 4.78$ & $4.56 \pm 2.45$ \\
\hline Total protein (mg/ml) & $1.09 \pm 0.62$ & $1.24 \pm 0.47$ & $1.16 \pm 0.56$ & $1.00 \pm 0.47$ \\
\hline a-amylase $(\mathrm{J} / \mathrm{ml})$ & $114.7 \pm 135.1$ & $95.4 \pm 36.6$ & $106.10 \pm 103.00$ & $113.36 \pm 82.00$ \\
\hline Peroxidase (mlU/ml) & $0.45 \pm 0.50^{e}$ & $0.66 \pm 0.44^{e, g}$ & $0.54 \pm 0.48$ & $0.46 \pm 0.31^{g}$ \\
\hline Calcium (mg/dL) & $3.27 \pm 1.52$ & $2.93 \pm 1.7$ & $3.12 \pm 1.45$ & $3.38 \pm 2.15$ \\
\hline Magnesium (mg/dL) & $0.50 \pm 0.38^{f}$ & $0.31 \pm 0.26^{\mathrm{f}, \mathrm{h}}$ & $0.41 \pm 0.34^{\mathrm{a}}$ & $0.60 \pm 0.38^{\mathrm{a}, \mathrm{h}}$ \\
\hline Inorganic phosphate (mg/dL) & $10.34 \pm 3.68$ & $11.71 \pm 3.50$ & $10.95 \pm 3.63$ & $10.33 \pm 3.86$ \\
\hline Fluoride (ppm) & $0.15 \pm 0.11^{i}$ & $0.15 \pm 0.09^{k}$ & $0.15 \pm 0.10^{b}$ & $0.21 \pm 0.10^{\mathrm{bi}, \mathrm{k}}$ \\
\hline Urea (mg/dL) & $33.57 \pm 16.36^{\prime}$ & $37.18 \pm 14.64^{\mathrm{m}}$ & $35.19 \pm 15.55^{c}$ & $25.21 \pm 10.78^{\mathrm{cll}, \mathrm{m}}$ \\
\hline Uric acid (mg/dL) & $2.64 \pm 1.09^{n}$ & $3.24 \pm 1.34^{\circ}$ & $2.90 \pm 1.23^{d}$ & $2.34 \pm 1.04^{\mathrm{d}, \mathrm{n}, \mathrm{o}}$ \\
\hline
\end{tabular}

iNS Idiopathic nephrotic syndrome

Significant difference at $P<0.05$ between $a-a, d-d, f-f, g-g, n-n$ and $o-o$

Significant difference at $\mathrm{P}<0.01$ between $\mathrm{b}-\mathrm{b}, \mathrm{c}-\mathrm{c}, \mathrm{e}-\mathrm{e}, \mathrm{h}-\mathrm{h}, \mathrm{i}-\mathrm{i}, \mathrm{k}-\mathrm{k}, \mathrm{I}-\mathrm{I}$ and $\mathrm{m}-\mathrm{m}$

Table 3 Logistic regression analysis for the presence or absence of the disease as dependent variable

\begin{tabular}{|c|c|c|c|c|c|c|}
\hline \multirow[t]{2}{*}{$\begin{array}{l}\text { Salivary parameters (independent variables } \\
\text { included into regression model) }\end{array}$} & \multicolumn{3}{|c|}{$\begin{array}{l}\text { Results of bivariate logistic regression } \\
\text { for dependent variable presence or absence } \\
\text { of the disease }\end{array}$} & \multicolumn{3}{|c|}{$\begin{array}{l}\text { Results of multivariate logistic } \\
\text { regression for dependent variable: } \\
\text { presence or absence of the disease }\end{array}$} \\
\hline & b & OR & $p$ & b & OR & P-value \\
\hline V & -0.304 & 0.738 & 0.730 & 1.348 & 0.299 & 0.366 \\
\hline $\mathrm{pH}$ & -0.628 & 0.533 & 0.092 & 1.832 & 0.605 & 0.385 \\
\hline$B C$ & 0.121 & 1.128 & 0.114 & 3.148 & 1.147 & 0.060 \\
\hline$P$ & 0.632 & 1.882 & 0.137 & 8.278 & 2.114 & 0.135 \\
\hline Amy & -0.001 & 0.999 & 0.704 & 2.710 & 0.997 & 0.261 \\
\hline SPO & 0.499 & 1.647 & 0.347 & 30.662 & 3.423 & 0.106 \\
\hline $\mathrm{Ca}$ & -0.079 & 0.924 & 0.495 & 3.540 & 1.264 & 0.213 \\
\hline $\mathrm{Mg}$ & -1.449 & 0.235 & $0.021^{*}$ & 1.098 & 0.093 & $0.013^{*}$ \\
\hline iPh & 0.046 & 1.047 & 0.416 & 2.512 & 0.921 & 0.352 \\
\hline$F$ & -6.024 & 0.002 & $0.009^{* *}$ & 1.006 & 0.006 & 0.082 \\
\hline U & 0.056 & 1.058 & $0.001^{* * *}$ & 2.912 & 1.069 & $0.004^{* *}$ \\
\hline UA & 0.441 & 1.554 & $0.022^{*}$ & 4.755 & 1.559 & 0.127 \\
\hline
\end{tabular}

$b$ logistic regression coefficient, $O R$ odds ratio, $V$ salivary flow rate, $B C$ buffer capacity, $P$ total protein, $A m y$ a-amylase, $S P O$ peroxidase, $C a$ calcium, $M g$ magnesium, $i P h$ inorganic phosphate, $F$ fluoride, $U$ urea, UA uric acid, $P$-value level of statistical significance

*Significant effect at $\mathrm{P}<0.05$

**Significant effect at $P<0.01$

***Significant effect at $\mathrm{P}<0.001$ 
discriminate the diseased and nondiseased participants. The accuracy for these variables ranged from 66.0 to 67.0\%, and the AUC ranged from 0.638 to 0.682 (Fig. 1). Similarly, the salivary levels of SPO and magnesium turned out to be weak markers to distinguish the participants with relapse from the remission phase of the disease because the accuracy was $70.2 \%$ and $68.1 \%$ and the AUC was 0.717 and 0.675 , respectively (Fig. 2).

\section{Relationship of oral health parameters and salivary constituents}

We did not find any significant correlation between oral health parameters and levels of the studied salivary components in either group of participants.

\section{Serum parameters}

The iNS patients demonstrated considerably higher mean levels of total cholesterol and triglycerides in the plasma than the reference range. Several individuals revealed concentrations of protein, uric acid, urea and inorganic phosphate, total cholesterol, triglycerides, creatinine and eGFR values that exceeded the upper limit of the reference ranges. In the relapse phase, compared with the remission phase of the disease, lower concentrations of protein, albumin, and calcium and higher contents of total cholesterol and triglycerides were found (Table 4).

\section{Relationship of studied constituents in blood and saliva}

We did not find any significant correlation between the same parameters in saliva and blood in the iNS participants, except for a trend of a positive significant
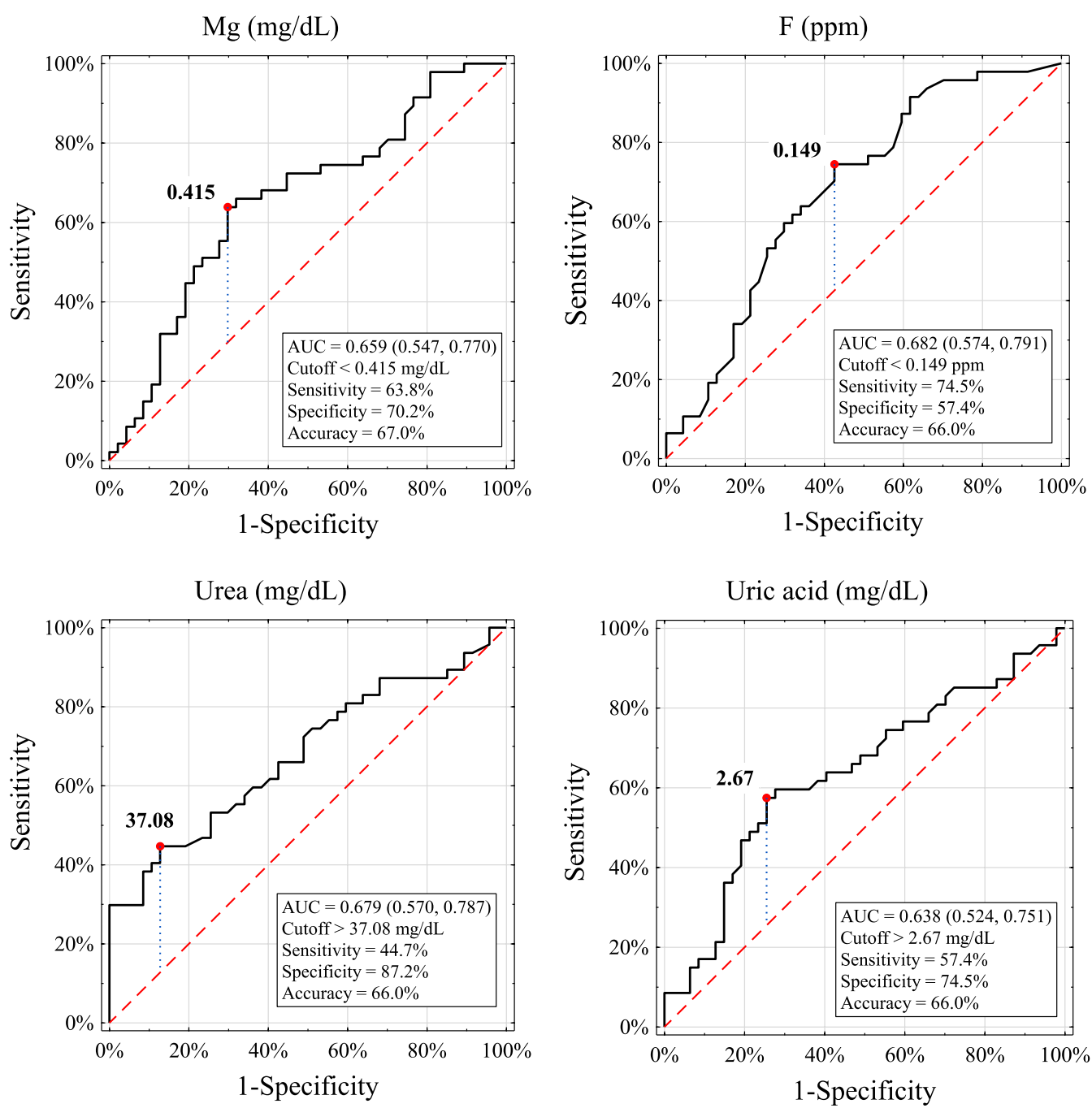

Fig. 1 ROC curves and cutoff values for salivary parameters those showed significant difference between the iNS patients and controls. Mg magnesium, $R O C$ receiver operating characteristic, AUC the area under the ROC curve 

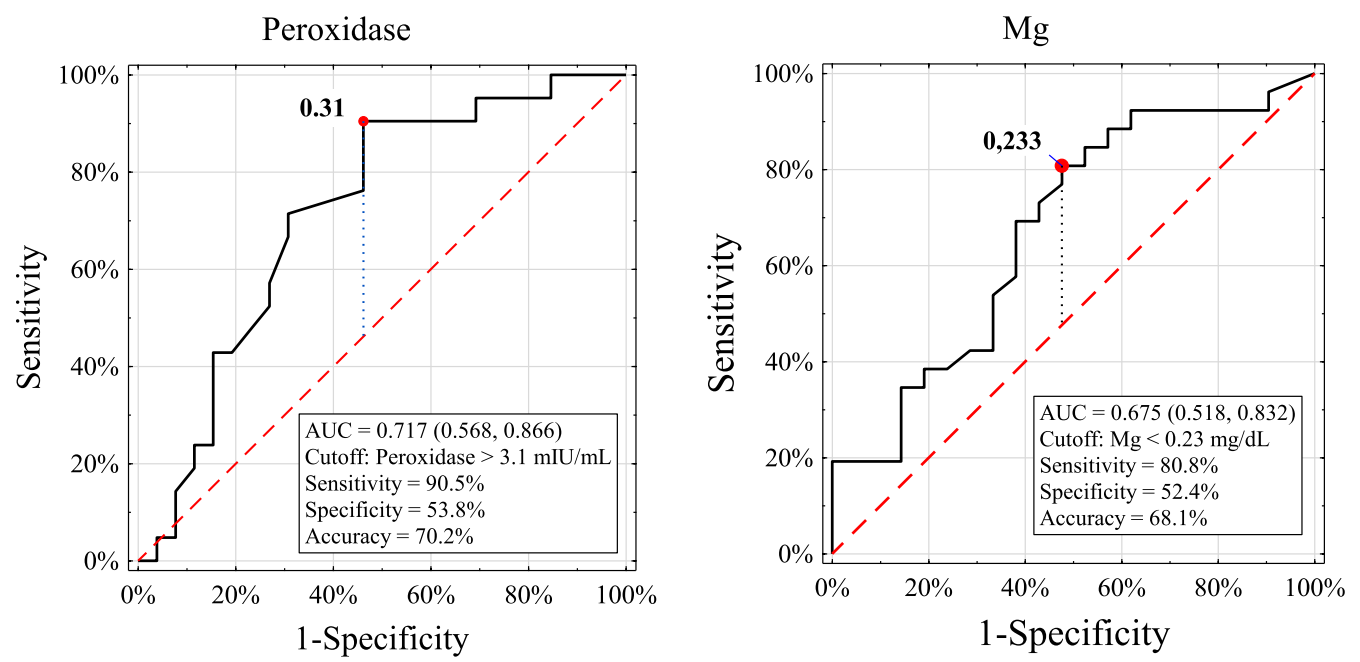

Fig. 2 ROC curves and cutoff values for salivary parameters those showed significant difference between the iNS patients with remission and relapse. $M g$ magnesium, $R O C$ receiver operating characteristic, $A \cup C$ the area under the ROC curve

Table 4 Blood laboratory data in children with remission and relapse of the disease

\begin{tabular}{|c|c|c|c|c|}
\hline \multirow[t]{3}{*}{ Blood parameters } & \multicolumn{4}{|c|}{ Idiopathic nephrotic syndrome participants } \\
\hline & $\begin{array}{l}\text { Remission } \\
n=26\end{array}$ & $\begin{array}{l}\text { Relapse } \\
n=21\end{array}$ & $\begin{array}{l}\text { Total } \\
n=47\end{array}$ & Reference range \\
\hline & Mean $\pm S D(\min -\max )$ & Mean $\pm S D(\min -\max )$ & Mean $\pm S D(\min -\max )$ & \\
\hline Protein (g/dL) & $6.74 \pm 0.95^{\mathrm{a}}(4.0-8.2)^{\mathrm{f}}$ & $4.96 \pm 0.81^{\mathrm{a}}(3.5-6.7)$ & $5.94 \pm 1.26(3.5-8.2)^{f}$ & $5.7-8$ \\
\hline Albumin (g/dL) & $4.14 \pm 0.76^{b}(2.1-5.1)$ & $2.55 \pm 0.64^{\mathrm{b}}(1.4-3.6)$ & $3.43 \pm 1.06(1.4-5.1)$ & $3.5-5.2$ \\
\hline Urea (mg/dL) & $26.3 \pm 7.2(11-44)^{f}$ & $29.8 \pm 15.0(10-72)^{f}$ & $27.9 \pm 11.3(10-72)^{f}$ & $11-43$ \\
\hline Uric acid (mg/dL) & $4.86 \pm 1.24(2.7-7.9)^{f}$ & $5.43 \pm 1.84(3.5-10.7)^{f}$ & $5.11 \pm 1.55(2.7-10.7)^{f}$ & $\begin{array}{l}\text { Girls: } 2.6-6.0 \\
\text { Boys: } 3.5-7.2\end{array}$ \\
\hline Calcium (mg/dL) & $9.74 \pm 0.60^{c}(8.3-10.6)$ & $9.13 \pm 0.84^{c}(7.4-10.4)$ & $9.47 \pm 0.77(7.4-10.6)$ & $8.8-10.8$ \\
\hline Magnesium (mg/dL) & $1.97 \pm 0.21(1.6-2.6)$ & $2.05 \pm 0.19(1.6-2.3)$ & $2.01 \pm 0.21(1.6-2.6)$ & $1.45-2.6$ \\
\hline Inorganic phosphate (mg/dL) & $4.75 \pm 0.64(3.5-5.8)^{f}$ & $4.79 \pm 0.94(3.2-7.7)^{f}$ & $4.77 \pm 0.77(3.2-7.7)^{f}$ & $2.5-5$ \\
\hline Total cholesterol (mg/dL) & $206 \pm 63^{d}(122-347)^{f}$ & $387 \pm 108^{d}(240-659)^{f}$ & $285 \pm 124(122-659)^{f}$ & $<170$ \\
\hline Triglycerides (mg/dL) & $134 \pm 125^{e}(40-677)^{f}$ & $276 \pm 190^{e}(135-969)^{f}$ & $199 \pm 172(40-969)^{f}$ & $\begin{array}{l}2-9 \text { years }<75 \\
10-17 \text { years }<90\end{array}$ \\
\hline Creatinine (mg/dL) & $0.59 \pm 0.17(0.32-1.09)^{f}$ & $0.64 \pm 0.12(0.67-0.92)$ & $0.62 \pm 0.15(0.32-1.09)^{f}$ & $0.3-1.0$ \\
\hline $\mathrm{eGFR}\left(\mathrm{ml} / \mathrm{min} / 1.73 \mathrm{~m}^{2}\right)$ & $128.02 \pm 18.42(98.25-160.6)^{f}$ & $121.11 \pm 21.16(87.28-187.69)^{f}$ & $124.19 \pm 20.32(87.28-187.69)^{f}$ & $\begin{array}{l}2-12 \text { years } 140 \pm 30 \\
13-21 \text { years } 126 \pm 22\end{array}$ \\
\hline
\end{tabular}

iNS Idiopathic nephrotic syndrome, eGFR estimated Glomerular Filtration Rate

Significant difference at $\mathrm{P}<0.01$ between $\mathrm{c}-\mathrm{C}$

Significant difference at $\mathrm{P}<0.001$ between $a-a, b-b, d-d, e-e$

${ }^{f}$ Individual values over reference range

correlation of uric acid $(\mathrm{r}=0.377, \mathrm{P}=0.051)$ in patients in the remission phase of the disease (Table 5).

\section{Discussion}

This preliminary study evaluated selected salivary components in pediatric patients with idiopathic steroidsensitive nephrotic syndrome. The null hypothesis was rejected, as there were differences in some studied salivary components between the iNS and healthy participants. We demonstrated that the disease is associated with significantly lower magnesium and fluoride concentrations and higher urea and uric acid contents in unstimulated mixed saliva.

iNS is characterized by complex abnormalities in blood tests and treatment by steroids, immunosuppressants or cytostatics, and dietary regimens, which may be reflected 
Table 5 Pearson correlation coefficients of the studied constituents in blood and saliva in iNS participants

\begin{tabular}{llll}
\hline Parameter & $\begin{array}{l}\text { Remission } \\
\mathbf{n}=\mathbf{2 6}\end{array}$ & $\begin{array}{l}\text { Relapse } \\
\mathbf{n}=\mathbf{2 1}\end{array}$ & $\begin{array}{l}\text { Total } \\
\mathbf{n}=\mathbf{4 7}\end{array}$ \\
\hline$P$ & $r=-0.007$ & $r=-0.102$ & $r=-0.125$ \\
Ca & $p=0.974$ & $p=0.659$ & $p=0.402$ \\
& $r=0.196$ & $r=-0.262$ & $r=0.017$ \\
Mg & $p=0.338$ & $p=0.251$ & $p=0.911$ \\
& $r=-0.189$ & $r=-0.261$ & $r=-0.245$ \\
iPh & $p=0.356$ & $p=0.267$ & $p=0.101$ \\
& $r=0.075$ & $r=-0.082$ & $r=-0.003$ \\
U & $p=0.717$ & $p=0.733$ & $p=0.986$ \\
& $r=-0.207$ & $r=-0.203$ & $r=-0.167$ \\
UA & $p=0.310$ & $p=0.377$ & $p=0.261$ \\
& $r=0.377$ & $r=-0.153$ & $r=0.105$ \\
& $p=0.051^{\circ}$ & $p=0.508$ & $p=0.482$ \\
\hline
\end{tabular}

iNS Idiopathic nephrotic syndrome, $P$ total protein, $\mathrm{Ca}$ calcium, $\mathrm{Mg}$ magnesium, $i P h$ inorganic phosphate, $U$ urea, $U A$ uric acid, $r$ Pearson correlation coefficient, $p$ level of statistical significance

- A trend to significant difference at $\mathrm{P}<0.05$

in the saliva composition. Unfortunately, we could not compare our results with those of others because data in the literature are scarce and concern the excretion of endogenous proteins (albumin, transferrin, IgG1, and IgG4) [24], salivary cortisol concentration [25] and salivary cytokines [26].

Salivary gland secretion in unstimulated conditions can be reflected by the measurements of flow rate, total protein concentration, and salivary $\alpha$-amylase activity to some extent. Salivary $\alpha$-amylase, which is produced by the salivary glands, is the main protein in the saliva and constitutes up to $50 \%$ of the total salivary protein [27]. However, we did not observe any significant differences in these parameters between the iNS patients and the controls. Therefore, undisturbed salivary gland activity could be suggested. Polak et al. [26] found a lower total protein concentration in the saliva of children with steroid-sensitive nephrotic syndrome than in the control group.

The salivary buffer capacity acts as an important factor in controlling the $\mathrm{pH}$ of the oral environment. The buffer capacity of saliva involves three major systems: carbonic acid/bicarbonate, phosphate, and protein [28]. We did not find any significant difference in the levels of $\mathrm{pH}$, buffer capacity, or inorganic phosphate between the iNS and healthy participants.

Several studies have emphasized the pathophysiological importance of oxidative stress in patients with nephrotic syndrome and its influence on the response of these patients to therapy [29-31]. Antioxidants can neutralize the negative effects of free radicals and reactive oxygen species (ROS) and reduce the effects of oxidative stress. Human saliva is rich in antioxidant compounds that comprise enzymes (e.g., peroxidase) and small molecules (e.g., uric acid). Salivary peroxidase is secreted by the acinar cells of salivary glands and catalyzes the oxidation of thiocyanate ions by hydrogen peroxide, thus preventing toxic accumulation of $\mathrm{H}_{2} \mathrm{O}_{2}$ [32]. Salivary peroxidase was suggested to be one of the salivary biomarkers in children with chronic kidney disease, but its level did not differ from that of the controls [33]. Our data also did not reveal any significant difference in SPO levels between all children with nephrotic syndrome and the healthy controls. However, the participants in the relapse phase of the disease revealed a significantly higher SPO level than those in the remission phase and the controls.

Serum uric acid is associated with many systemic conditions, including kidney and metabolic disorders. High uric acid levels have been found to be associated with a significant rapid decline in eGFR and can be considered a potential modifiable factor of chronic kidney disease progression [34]. In addition, uric acid is known as a scavenger of oxyradicals, a chelator of metal ions and an important antioxidant in plasma. Moreover, a correlation between uric acid concentrations in the saliva and plasma was noticed, and thus salivary uric acid can be used for monitoring the status of hyperuricemia [35]. We obtained a significantly higher concentration of salivary uric acid in iNS participants than in the controls, and some were higher in children with relapse than in those in the remission phase of the disease.

The elevated level of salivary urea was observed in patients with chronic kidney disease and was correlated with its blood content [36]. Our data showed only a trend of such a relationship. However, we noticed a significantly higher concentration of urea in the saliva of the iNS children than in the healthy children, and there was no difference between the patients with relapse and those in remission.

Patients with nephrotic syndrome can exhibit calcium homeostasis disturbance, which is assigned to the loss of various plasma proteins and minerals in urine and steroid therapy [37]. Significantly lower total calcium content in the serum was found in pediatric patients with steroid-resistant nephrotic syndrome compared with the controls, which, in addition, was lower in the relapse phase than in the complete remission phase [38]. Our results did not reveal any significant difference in salivary calcium between the iNS children and the controls or between patients with relapse and those in the remission phase of the disease.

A study on serum magnesium showed a significantly lower level in nephrotic syndrome patients than in controls. It has been deduced that the measurement of 
serum magnesium in children with acute nephropathy could be useful for early diagnosis and improving therapy [39]. Similarly, our results showed a significantly lower salivary magnesium concentration in the iNS children than in the controls and a lower magnesium level in patients with relapse than in those in remission.

An elevated serum phosphate level in nephrotic syndrome was found to be associated with the severity of the disease regardless of eGFR value and age [40]. However, no significant difference in serum phosphorus was found between patients with steroid-resistant nephrotic syndrome and the controls or between patients in complete remission and those with relapse [38]. Our data did not reveal any significant difference in the content of inorganic phosphate in the saliva between the iNS and healthy participants or in relation to the phase of the disease.

The sources of fluoride intake are diet and the fluoride compounds used for caries prevention, such as fluoridated water, fluoride supplements, and fluoridated toothpaste and mouth rinses when swallowed. The elimination of absorbed fluoride occurs almost exclusively through the kidney [41]. The excretion of fluoride is lower if the patient suffers from chronic renal failure, which leads to higher concentrations of fluoride in the serum and bone [42]. All participants in this study consumed drinking water with a low natural content of fluoride $(<0.3 \mathrm{ppm})$, and similar proportions of iNS and healthy participants declared the use of fluoridated dentifrice and professional topical application of fluoride specimens. We found a significantly lower concentration of fluoride in the saliva in the iNS group than in the controls.

However, despite the significant differences in mean magnesium, fluoride, urea and uric acid levels between the iNS and healthy participants, ROC curve analysis revealed that the discriminatory power of these variables for the differentiation of children with and without disease was weak. Similarly, salivary levels of peroxidase and magnesium were weak tests to identify iNS patients in the relapse phase of the disease. This finding indicates that the studied salivary parameters cannot be used as markers accurately differentiating iNS and healthy participants and those with relapse of the disease.

This study has some limitations. We evaluated only selected salivary parameters and thus could not fully characterize all potential changes in the salivary components. Moreover, we did not compare the same studied components in the saliva and the blood in all participants. The strength of the study was that the iNS and healthy participants subjected to the investigation did not differ significantly in the number of caries-affected primary and permanent teeth and gingival condition, which potentially could affect the studied salivary components.

Future long-term prospective investigations are needed to elucidate the possible impact of the disease course and treatment on the levels of salivary constituents in iNS patients.

\section{Conclusions}

Within the limitations of the study, it may be stated that the levels of urea, uric acid, magnesium and fluoride in saliva were associated with disturbances occurring in the course of idiopathic steroid-sensitive nephrotic syndrome. Salivary levels of peroxidase and magnesium can be related to the phase of the disease. However, their measurements cannot serve as a noninvasive tool in diagnosing iNS and the phase of the disease.

\section{Abbreviations \\ DMFT: Decay, missing and filled permanent teeth; dmft: Decay, missing and filled primary teeth; API: Approximal Plaque Index; GI: Gingival Index; eGFR: Estimated glomerular filtration rate; V: Salivary flow; BC: Buffer capacity; P: Total protein; Amy: a-Amylase; SPO: Salivary peroxidase; Ca: Calcium; Mg: Magne- sium; iPh: Inorganic phosphate; F: Fluoride; U: Urea; UA: Uric acid; WHO: World Health Organization; CKD: Chronic kidney disease; iNS: Idiopathic nephrotic syndrome; ROC: Receiver operating characteristic; AUC: The area under the ROC curve.}

\section{Declarations}

Ethics approval and consent to participate

The study protocol was approved by the Bioethics Committee of Wroclaw Medical University (Permission No. KB-343/2016) in accordance with the Declaration of Helsinki. Participation in the study was voluntary and anonymous, and the collected data was treated confidentially. Written informed consent was obtained from a parent or guardian for participants under 16 years old.

\section{Consent for publication}

Not applicable.

Availability of data and materials

The datasets used and analyzed during the current study are available from the corresponding author on request.

\section{Competing interests}

The authors declare that have no competing interests related to this study.

\section{Funding}

This study was supported by a grant from the Wroclaw Medical University, Poland (Grant No. ST-B010.16.044). The funding body played no role in the study design, data collection, analysis and interpretation, and manuscript writing.

\section{Authors' contributions}

AWK, KJ, MMD and IP performed the oral clinical examination, collected the questionnaire data and salivary samples. KP performed the medical examination and gathered the blood parameters. IM performed medical examination and drafting. UK designed the study, performed analysis and interpretation of the data, drafted and edited the manuscript. All authors read and approved the final manuscript.

\section{Acknowledgements}

The authors thank the children and adolescents and their parents for participation in the study. 


\author{
Author details \\ 1 Department of Conservative Dentistry and Pedodontics, Wroclaw Medical \\ University, Krakowska 26, 50-425 Wrocław, Poland. ${ }^{2}$ Department and Clinic \\ of Pediatric Nephrology, Wroclaw Medical University, Borowska 213, \\ 50-556 Wrocław, Poland.
}

Received: 31 Auqust 2020 Accepted: 20 December 2020 Published online: 07 January 2021

\section{References}

1. Eddy AA, Symons JN. Nephrotic syndrome in childhood. Lancet Lond Engl. 2003;369:629-39.

2. Pasini A, Benetti E, Conti G, Ghio L, Lepore M, Massella L, Molino D, Peruzzi L, Emma F, Fede C, Trivelli A, Maringhini S, Materassi M, Messina G, Montini G, Murer L, Pecoraro C, Pennesi M. The Italian Society for Pediatric Nephrology (SINePe) consensus document on the management of nephrotic syndrome in children: Part I—diagnosis and treatment of the first episode and the first relapse. Ital J Pediatr. 2017. https://doi.org/10.1186/s13052-017-0356-x.

3. Shin Jl, Kronbichler A, Oh J, Meijers B. Nephrotic syndrome: genetics, mechanism, and therapies. Biomed Res Int. 2018;2018:6215946. https://doi. org/10.1155/2018/6215946.

4. Mühlig AK, Lee JY, Kemper MJ, Kronbichler A, Yang JW, Lee JM, Shin J, Oh J. Levamisole in children with idiopathic nephrotic syndrome: clinical efficacy and pathophysiological aspects. J Clin Med. 2019;8(6):860. https://doi. org/10.3390/jcm8060860.

5. Noone DG, lijima K, Parekh R. Idiopathic nephrotic syndrome in children. Lancet Lond Engl. 2018;392:61-74.

6. Arunkumar S, Arunkumar JS, Burde KN, Shankuntala GK. Developments in diagnostic applications of saliva in oral and systemic diseases - a comprehensive review. J Sci Inov Res. 2014;3:372-87.

7. Humphrey SP, Williamson RT. A review of saliva: normal composition, flow, and function. J Prosthet Dent. 2001;85:162-9.

8. Mittal S, Bansal V, Garg S, Arteja G, Bansal S. The diagnostic role of saliva-a review. J Clin Exp Dent. 2011;3:314-20.

9. Malamud D. Saliva as a diagnostic fluid. Dent Clin N Am. 2011;5:159-78.

10. Nagler RM. Saliva analysis for monitoring dialysis and renal function. Clin Chem. 2008:54:1415-7.

11. Nagarathinam AE, Kumar TD, Kumar AR, Vasanthira K, Laksmi RS, Jayant VS. Salivary urea and creatinine as a diagnostic marker of chronic kidney disease_-review. J Dent Med Sci. 2017;16:95-100.

12. Renda R. Can salivary creatinine and urea levels be used to diagnose chronic kidney disease in children as accurately as serum creatinine and urea levels? A case-control study. Ren Fail. 2017;39:452-7.

13. Bilancio G, Cavallo P, Lombardi C, Guarino E, Cozza V, Giordano F, Palladino G, Cirillo M. Saliva for assessing creatinine, uric acid, and potassium in nephropathic patients. BMC Nephrol. 2019;20(1):242. https://doi.org/10.1186/s1288 2-019-1437-4

14. Arregger AL, Cardoso EML, Tumilasci O, Contreras N. Diagnostic value of salivary cortisol in end stage renal disease. Steroids. 2008;73:77-82.

15. Savica V, Calò LA, Granata A, Caldarera R, Cavaleri A, Santoro D, Monardo P, Savica R, Muraca U, Bellinghieri G. A new approach to the evaluation of hyperphosphatemia in chronic kidney disease. Clin Nephrol. 2007;68:216-21

16. Kaczmarek U, Wrzyszcz-Kowalczyk A, Jankowska K, Prościak K, MysiakDębska M, Przywitowska I, Makulska I. Oral health conditions in children with idiopathic nephrotic syndrome: a cross-sectional study. BMC Oral Health. 2020;20(1):213. https://doi.org/10.1186/s12903-020-01197-1.

17. STROBE Statement. Strengthening the reporting of observational studies in epidemiology. STROBE checklists, Version 4 as published in Oct/Nov 2007. Checklist for case-control studies. http://www.strobe-statement.org/index .php?id=available-checklists. Accessed 15 Dec 2020.

18. Select statistical services. Comparing two means-sample-size. https:// select-statistics.co.uk/calculators/sample-size-calculator-two-means/. Accessed 18 Oct 2020

19. World Health Organization. Oral health surveys_-basic methods. 5th edn; 2013. http://www.who.int/oral_health/publications/9789241548649/en/. Accessed 20 Oct 2020.

20. Wolf HF, Rateitschak EM, Rateitschak KH, Hassel TM. Periodontologie. In: Rateitschak KH, Wolf HF, editors. Color atlas of dental medicine. 3rd ed. New York: George Thieme Stuttgart; 2005. p. 68-9.
21. Lowry OH, Rosebrough NJ, Farr AL, Randall RJ. Protein measurement with the Folin phenol reagent. J Biol Chem. 1951;193:265-75.

22. Mansson-Rahemtulla B, Baldone DC, Pruitt KM, Rahemtulla F. Specific assays for peroxidases in human saliva. Arch Oral Biol. 1986;31:661-8.

23. Schwartz GJ, Muñoz A, Schneider MF, Mak RH, Kaskel F, Warady BA, Furth SL. New equations to estimate GFR in children with CKD. J Am Soc Nephrol. 2009;20:629-37.

24. Neuhaus TJ, Shah V, Barratt TM. Salivary excretion of endogenous proteins in nephrotic syndrome in children. Pediatr Nephrol. 1997;11:411-4.

25. Carlotti AP, Franco PB, Elias LL, et al. Glucocorticoid receptors, in vitro steroid sensitivity, and cytokine secretion in idiopathic nephrotic syndrome. Kidney Int. 2004;65(2):403-8.

26. Polak D, Borovitz Y, Clyman-Levy D, Klein Y, Bernfeld N, Davidovits M, Davidovich E. Salivary cytokines in children with nephrotic syndrome versus Healthy children: a comparative study. J Clin Med. 2020;9(9):2691.

27. Noble RE. Salivary alpha-amylase and lysozyme levels: a non-invasive technique for measuring parotid vs submandibular/sublingual gland activity. J Oral Sci. 2000:42:83-6.

28. Bardow A, Moe D, Nyvad B, Nauntofte B. The buffer capacity and buffer systems of human whole saliva measured without loss of $\mathrm{CO}_{2}$. Arch Oral Biol. 2000:45:1-12.

29. Dogra G, Ward N, Croft KD, Mori TA, Barrett PH, Herrmann SE, Irish AB, Watts GF. Oxidant stress in nephrotic syndrome: comparison of F(2)-isoprostanes and plasma antioxidant potential. Nephrol Dial Transplant. 2001;16:1626-30.

30. Kamireddy R, Kavuri S, Devi S, Vemula H, Chandana D, Harinarayanan S, James R, Rao A. Oxidative stress in pediatric nephrotic syndrome. Clin Chim Acta. 2002:325:147-50.

31. Reddy P, Sindgikar P, Shenoy RD, Shenoy V. Oxidative stress in childhood steroid sensitive nephrotic syndrome and its correlation with DNA damage. Int J Contemp Pediatr. 2016;3:768-72.

32. Battino M, Ferreiro MS, Gallardo I, Newman HN, Bullon P. The antioxidant capacity of saliva. J Clin Periodontol. 2002;29:189-94.

33. Maciejczyk M, Szulimowska J, Skutnik A, Taranta-Janusz K, Wasilewska A, Wiśniewska N, Zalewska A. Salivary biomarkers of oxidative stress in children with chronic kidney disease. J Clin Med. 2018;7(8):209.

34. Tsai CW, Lin SY, Kuo CC, Huang CC. Serum uric acid and progression of kidney disease: a longitudinal analysis and mini-review. PLOS ONE. 2017:12(1):e0170393.

35. Riis JL, Bryce Cl, Matin MJ, Stebbins JL, Kornienko O, van Huisstede L, Granger DA. The validity, stability, and utility of measuring uric acid in saliva. Biomark Med. 2018;12:583-96.

36. Lasisi TJ, Raji YR, Salako BL. Salivary creatinine and urea analysis in patients with chronic kidney disease: a case control study. BMC Nephrol. 2016;1:10. https://doi.org/10.1186/s12882-016-0222-x.

37. Esmaeeili M, Azarfar A, Hoseinalizadeh S. Calcium and vitamin D metabolism in pediatric nephrotic syndrome; an update on the existing literature. Int J Pediatr. 2015;3(21):103-9.

38. Sharma S, Dabla PK, Kumar M. Status of metabolic bone disease in pediatric steroid resistant nephrotic syndrome: study from North India. Ann Clin Lab Res. 2018;6:235. https://doi.org/10.21767/2386-5180.100235.

39. Teslariu O, Mititelu-Tartău L, Stârcea M, Crenguta IM, Nechifor M. Magnesium in pediatric nephrotic syndrome. Rev Med Chir Soc Med Nat lasi. 2016;120:818-23.

40. Sexton DJ, Kinsella SM, Eustace JA. Serum phosphate varies with degree of proteinuria in nephrotic syndrome and is associated with elevated pulse wave velocity. J Nephrol. 2013;26:540-54

41. World Health Organization. Basic methods for assessing renal fluoride excretion in community prevention programmes for oral health. World Health Organization, 2014. https://apps.who.int/iris/handle/10665/112662. Accessed 25 Oct 2020.

42. National Kidney Foundation: Fluoride intake in chronic kidney disease. National Kidney Foundation. New York, USA, 2008. https://www.kidney.org/ sites/default/files/docs/fluoride_intake_in_ckd.pdf. Accessed 28 Oct 2020.

\section{Publisher's Note}

Springer Nature remains neutral with regard to jurisdictional claims in published maps and institutional affiliations. 